\title{
Análise do processo de preparação da produção no desenvolvimento de novos produtos por meio de um estudo de caso em uma empresa do setor siderúrgico
}

\author{
Angelo Varandas Junior ${ }^{\mathrm{a} *}$, Paulo Augusto Cauchick Miguel ${ }^{\mathrm{b}}$ \\ a*varandas@usp.br, USP, Brasil \\ bcauchick@usp.br, USP, Brasil
}

\begin{abstract}
Resumo
A demanda por novos produtos tem aumentado em algumas empresas do setor siderúrgico, indicando uma crescente preocupação com o desempenho do processo de desenvolvimento de produtos (PDP), que depende de vários elementos conceituais importantes apontados na literatura. Em uma empresa siderúrgica, um fator relevante é o projeto do processo de produção, devido à característica de ser um processo de fabricação contínuo e por, geralmente, envolver investimentos significativos na fase de preparação da produção. Nesse contexto, o presente trabalho busca realizar uma análise desta fase em uma empresa siderúrgica. Pretende-se, por meio da abordagem metodológica de estudo de caso, identificar práticas organizacionais, focando nos aspectos operacionais e suas interfaces, envolvendo as áreas funcionais de marketing, engenharia do produto e manufatura. Também é tratada no trabalho a integração dos times multidisciplinares, a tomada de decisão e os critérios para avaliação dos resultados do PDP. 0 trabalho conclui que a empresa analisada utiliza-se de práticas que estruturam a preparação da produção e que a integração interfuncional das áreas é o que se destaca para o sucesso do PDP.
\end{abstract}

Palavras-chave

Processo de desenvolvimento de produtos. Projeto do processo. Setor siderúrgico.

\section{Introdução}

0 processo de desenvolvimento de produto (PDP) é essencial na construção e sustentação de vantagens competitivas, sendo considerado como uma das mais importantes atividades nas empresas para fortalecer sua posição mercadológica. Em geral, este processo consiste em um conjunto de atividades que são executadas na definição de novos produtos, incluindo a tomada de decisões, em que alternativas são identificadas e avaliadas com critérios previamente definidos. Sua função é integrar todos esses critérios e otimizá-los, considerando as restrições existentes de complexidade do produto, do processo de produção, de aspectos organizacionais e, também, de geração de custos com retrabalhos (CLARK; FUJIMOTO, 1991).

A demanda pela introdução de novos produtos tem aumentado intensamente, justificando uma preocupação com a eficiência e a eficácia do PDP.

Esse desempenho depende da gestão do PDP (CHENG, 2000), que deve ir além da busca por menor custo, sendo também condições desejáveis para a competitividade a colocação do produto no mercado o mais rapidamente possível, a manufaturabilidade do produto e a criação e o fortalecimento, a cada projeto, das capacitações requeridas para o PDP (MUNDIM et al., 2002).

Acompanhando estas mudanças nos produtos, o PDP passa por uma evolução, que pode ser dividida em três eras distintas (ROZENFELD et al., 2006): i) desenvolvimento sequencial de produtos, que tinha como foco principal a divisão de tarefas, especialização e ênfase nas áreas funcionais; ii) desenvolvimento integrado de produtos, que se caracteriza por englobar as abordagens de engenharia simultânea, do funil de desenvolvimento de Clark e Wheelwright 
(1992) e do processo denominado de stage-gates por Cooper (1993); e iii) novas abordagens para desenvolvimento integrado de produtos, que englobam o desenvolvimento lean (baseado nos princípios da manufatura enxuta, que busca reduzir desperdícios), o design for six sigma - DFSS (baseado nos conceitos do seis sigma, que otimiza soluções de projeto com a utilização de ferramentas estatísticas), e o gerenciamento do ciclo de vida de produto (que busca a integração das etapas do ciclo de vida do produto).

Alguns trabalhos clássicos destacam que o PDP é constituído por quatro macrotópicos interrelacionados (CLARK; FUJIMOTO, 1991; CLARK; WHEELWRIGHT, 1992;1993; CLAUSING, 1994; PUGH, 1996; PRASAD, 1997): i) estratégico, que compreende a gestão do portfolio, desempenho do processo, condução de alianças e parcerias, condução de relações interfuncionais e interdepartamentais; ii) organizacional, que engloba a gestão da estrutura organizacional, liderança e capacitação dos funcionários; iii) atividades/informações, que se preocupam com as etapas operacionais e com a normalização e controle das informações geradas; e iv) recursos, que são as técnicas, métodos e ferramentas de apoio.

A visão atual do PDP é de um processo de negócio que foca o cliente final, integrando as pessoas e áreas funcionais em uma busca de simultaneidade na realização das tarefas (CARTER; BAKER, 1992; CLAUSING, 1994; ROZENFELD, 1996). A partir deste conceito de processo de negócios, diversos autores dividem o PDP em fases distintas, visando sua melhor operacionalização, como Clark e Wheelwright (1992), que o dividem em quatro fases: i) desenvolvimento do conceito; ii) planejamento do produto; iii) engenharia do produto/processo; e iv) produção piloto/aumento da produção, intercaladas por uma revisão de fases (geralmente denominado de gate), que consiste em um ponto de decisão gerencial que avalia a possibilidade de continuidade ou não do projeto e os riscos envolvidos nesta decisão (COOPER, 1993).

Analisando a importância de cada fase do PDP, verifica-se que é na fase de engenharia do processo de produção (ou preparação de produção) que os desenhos detalhados do produto são traduzidos em planos de fabricação. Os dados e informações dessa fase incluem definições e dados necessários para fabricação do produto. Nesta fase, é comum ocorrerem alterações de projeto, o que implica na perda de trabalhos previamente realizados (BARKAN, 1992). Ainda segundo o autor previamente citado, as modificações de engenharia são consideradas problemas de primeira ordem no PDP, que podem ser utilizados como item de controle para medir a eficácia do processo de projeto do produto. Afinal, os reprojetos tardios geram impactos diretos sobre 0 custo, tempo de desenvolvimento e impactos indiretos sobre a qualidade dos produtos (ROZENFELD, 1996).

Essa é uma realidade que ocorre também nas empresas siderúrgicas, foco deste estudo, em função da introdução de novos produtos motivada pelo mercado e também da importância da preparação da produção para essas empresas. A estratégia de crescimento da siderurgia brasileira baseia-se no enobrecimento de produtos e na renovação tecnológica em mudanças técnicas incrementais nos processos de produção (PAULA, 2002). Assim, ter um PDP estruturado é também uma condição necessária para estas empresas, devido a sua complexidade, principalmente de caráter organizacional, com base na classificação de Clark e Fujimoto (1991).

Tal como em vários outros setores industriais, as empresas do setor siderúrgico apresentam hoje uma complicada interface organizacional, que compreende o relacionamento entre diferentes pessoas, recursos, conhecimento e funções da empresa, tais como as áreas funcionais de marketing, engenharia do produto e manufatura. Além disso, para se desenvolver um produto novo, necessita-se da interação destas interfaces da organização, que são gerenciadas por diferentes pessoas, com visões distintas da importância do PDP como um negócio da empresa, trazendo dificuldades para a sua gestão. Identifica-se ainda que no projeto do processo de produção existe a necessidade de uma maior estruturação na sua gestão e utilização de métodos de suporte ao PDP, devido à intensificação de problemas de interface organizacional e aumento de custos do projeto nesta fase. 0 conceito de interface organizacional utilizado neste trabalho refere-se ao gerenciamento de diversas funções da empresa, envolvidas no PDP, com objetivos diferentes quanto a este processo, conforme estabelecido por Altamirano (1999).

Apesar da complexidade organizacional do setor siderúrgico e da necessidade de gerenciar e desenvolver novos produtos, a maioria dos trabalhos realizados na siderurgia investiga apenas aspectos mais gerais de P\&D, inovação tecnológica para metalurgia, e expansão via aquisições e internacionalização. Considerando que os estudos que abordam especificamente a fase de preparação da produção na indústria siderúrgica são escassos e que há um crescimento constante da demanda por novos produtos, surge então a necessidade de gerenciar as complexidades operacionais para se ter sucesso no PDP.

Nesse contexto, o presente trabalho tem como objetivo avaliar o PDP em uma empresa do setor siderúrgico, identificando suas práticas organizacionais, por meio da abordagem metodológica de estudo de caso. 0 trabalho concentra-se na fase de preparação 
da produção (também denominado neste trabalho de projeto de processo de produção), em função de sua relevância, destacada anteriormente. A partir do referencial teórico, descrito a seguir, são apresentados os resultados dessa investigação, obtidos pelos métodos e técnicas de pesquisa adotados, descritos mais a frente no texto.

\section{Referencial teórico}

0 desenvolvimento do referencial teórico deste trabalho é realizado conforme ilustra a Figura 1. Inicia-se com uma etapa de "varredura horizontal" conforme sugerido por Fleury (2010). Esta varredura horizontal aborda os principais temas relacionados ao PDP. Depois desta etapa, é realizado um aprofundamento vertical, ou seja, uma busca bibliográfica visando afunilar o conceito de PDP para a fase de preparação da produção do PDP. Com esses dados da literatura, identificam-se os conceitos teóricos a serem investigados, desdobrados em questões de pesquisa, destacados no item de métodos e técnicas de pesquisa.

Realizou-se primeiramente uma busca bibliográfica, considerando, principalmente, o portal de periódicos da CAPES (Coordenação de Aperfeiçoamento de Pessoal de Nível Superior), além de bibliotecas e alguns sites, considerando majoritariamente artigos, mas também dissertações e teses. Com a análise do material inicialmente encontrado, foi-se delineando o contorno do tema "projeto do processo (de produção) no PDP”. Na busca bibliográfica, foram resgatados 113 trabalhos de diferentes fontes e foram selecionadas 44 publicações mais diretamente relacionadas ao projeto do processo. Em uma análise bibliométrica inicial das fontes, constatou-se que a abordagem metodológica de pesquisa mais adotada foi o estudo de caso (40\%), seguido pelo levantamento tipo survey (32,5\%), trabalhos teórico-conceituais (15\%) e revisões da literatura (12,5\%). A abordagem das publicações, quanto à natureza dos dados e respectivos métodos, divide-se em qualitativa $(48,3 \%)$ e quantitativa $(51,7 \%)$, nela utilizaram-se como principais instrumentos de

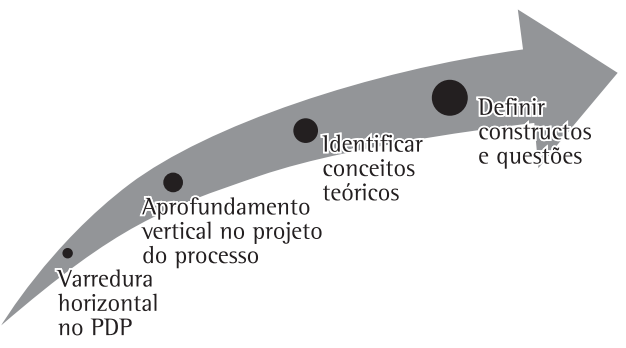

Figura 1. Etapas para elaboração do referencial teórico. coleta de dados entrevistas $(50,0 \%)$ e questionários $(28,6 \%)$, sendo que, em $21,4 \%$, utilizam-se ambos os instrumentos de coleta de dados. Nesta etapa de desenvolvimento do referencial teórico, conseguiu-se identificar elementos conceituais importantes relacionados ao PDP, citado por diversos autores que pesquisam o tema, apresentados no Quadro 1.

Os elementos conceituais importantes encontrados nesta busca foram analisados de acordo com a especificidade de cada um no PDP e foram selecionados pela importância associada às questões de pesquisa da proposta do trabalho, cuja apresentação é feita a seguir. Na verdade, os conceitos e importância destes tópicos da literatura sobre o PDP se inter-relacionam e se agrupam nos quatro macrotópicos do PDP, anteriormente citados (estratégico; organizacional; atividades/informações; e recursos). Devido aos tópicos de destaque na literatura (mostrados no Quadro 1) não abordarem especificamente a fase de projeto do processo de produção, foram aplicados questionários de avaliação de importância de cada fase do PDP (desenvolvimento do conceito, planejamento do produto, engenharia do produto/processo e produção piloto/aumento da produção), direcionados às áreas envolvidas no desenvolvimento de novos produtos do caso analisado. Desse modo, são considerados no presente trabalho apenas os resultados mais relevantes para o foco escolhido ("projeto do processo de produção"), no contexto do setor siderúrgico. Essa decisão é destacada a seguir, apresentando as etapas de condução do estudo de caso.

\section{Abordagem metodológica}

0 presente trabalho apresenta as seguintes características, segundo diversos autores (GODOY, 1995; YIN, 2001; VOSS; TSIKRIKTSIS; FROHLICH, 2002): análise indutiva; dados de natureza qualitativa; caráter descritivo das variáveis e objetivos gerais da pesquisa de cunho exploratório. A partir dessas características, descritas a seguir, a abordagem de estudo de caso é adotada.

A análise é indutiva, pois a linha de análise é do específico para o geral, embora com limitações na generalização dos resultados por tratar-se de somente uma unidade de análise. Os dados são de natureza qualitativa, devido ao tipo de variáveis e respectivos métodos, cujos resultados são representados de forma descritiva, com algumas relações (restritas) de causalidade. 0 trabalho é de natureza exploratória, pois a literatura é relativamente limitada no foco escolhido, seja pelo tema no nível teórico (projeto do processo de produção), seja pela investigação empírica no setor siderúrgico nesse tema. Tanto o contexto quanto o fenômeno são importantes no presente 
Quadro 1. Os principais tópicos relacionados ao PDP encontrados na literatura.

\begin{tabular}{|c|c|c|}
\hline $\begin{array}{l}\text { Principais } \\
\text { tópicos }\end{array}$ & Referências selecionadas & Abordagem \\
\hline $\begin{array}{c}\text { Ambiente de } \\
\text { incerteza no PDP }\end{array}$ & $\begin{array}{l}\text { Kenny (2003); } \\
\text { Van Oorschot, Bertrand e } \\
\text { Rutte (2005); } \\
\text { Bstieler; Gross (2003) }\end{array}$ & $\begin{array}{l}\text { É o desafio de gerenciar as incertezas envolvidas no processo, no qual as decisões de maior } \\
\text { impacto têm que ser tomadas no momento em que existe maior grau de incerteza. }\end{array}$ \\
\hline $\begin{array}{c}\text { Aprendizagem do } \\
\text { time no PDP }\end{array}$ & $\begin{array}{l}\text { Akgun, Lynn e } \\
\text { Byrne (2006) }\end{array}$ & $\begin{array}{l}\text { A aprendizagem se dá principalmente pela troca de informações obtidas por meio da } \\
\text { experiência no desenvolvimento, e o mais importante é não se esquecer de documentá-las. }\end{array}$ \\
\hline $\begin{array}{l}\text { Colaboração } \\
\text { e comunicação } \\
\text { no PDP }\end{array}$ & $\begin{array}{l}\text { Nambisan (2003); } \\
\text { Nobelius (2004); } \\
\text { Haque (2003); Cormican; } \\
\text { O'Sullivan (2004) }\end{array}$ & $\begin{array}{l}\text { A comunicação refere-se à troca de informaçães, isso vale para os tipos verbais e escritos. A } \\
\text { colaboração diferencia-se da comunicação devido ao foco em aspectos como trabalho em } \\
\text { grupo, compartilhamento de recursos, confiança mútua, e objetivo e visão comuns, ou seja, } \\
\text { aspectos mais informais e subjetivos. }\end{array}$ \\
\hline $\begin{array}{c}\text { Cumprimento de } \\
\text { prazos no PDP }\end{array}$ & $\begin{array}{l}\text { Syamil, Dol e } \\
\text { Apigian (2004) }\end{array}$ & $\begin{array}{l}\text { Cumprir os prazos pré-estabelecidos para que não ocorra atraso e aumento de custo do } \\
\text { projeto e demora no lançamento do novo produto no mercado. }\end{array}$ \\
\hline $\begin{array}{l}\text { Definição de } \\
\text { responsabilidades } \\
\text { no PDP }\end{array}$ & $\begin{array}{l}\text { Abdomerovic; } \\
\text { Blakemore (2002); } \\
\text { Fredericks (2005) }\end{array}$ & $\begin{array}{l}\text { Definir os times e especialistas responsáveis pela condução do projeto, definindo seus papéis, } \\
\text { contribuição de cada um e suas responsabilidades. }\end{array}$ \\
\hline $\begin{array}{l}\text { Diretriz para } \\
\text { gerentes de } \\
\text { projeto }\end{array}$ & $\begin{array}{l}\text { Akgun, Lynn e } \\
\text { Byrne (2006) }\end{array}$ & $\begin{array}{l}\text { Os gerentes de projeto devem melhorar o desempenho do time, resolver conflitos, isolar os } \\
\text { times de problemas exteriores e prover recursos. Também deve propor um bom ambiente de } \\
\text { trabalho e ter uma visão ampla sobre o caminho a ser trilhado pelo time. }\end{array}$ \\
\hline \begin{tabular}{c|} 
Duração \\
do ciclo de \\
desenvolvimento \\
de produtos
\end{tabular} & Griffin (1997) & $\begin{array}{l}\text { Para que se tenha um melhor controle do projeto e se crie interdependência entre as } \\
\text { atividades, dividem-se os projetos em algumas fases constituindo o chamado ciclo de vida } \\
\text { do projeto, que define quais técnicas de trabalho serão utilizadas e quais pessoas estarão } \\
\text { envolvidas em cada fase. }\end{array}$ \\
\hline $\begin{array}{c}\text { Entender os } \\
\text { problemas das } \\
\text { áreas envolvidas } \\
\text { no PDP }\end{array}$ & $\begin{array}{l}\text { Abdomerovic e } \\
\text { Blakemore (2002) }\end{array}$ & $\begin{array}{l}\text { Através da integração busca-se entender as limitações e variáveis de processo envolvidas no } \\
\text { desenvolvimento do produto. }\end{array}$ \\
\hline $\begin{array}{l}\text { Envolvimento da } \\
\text { alta gerência no } \\
\text { PDP }\end{array}$ & $\begin{array}{l}\text { Bonner, Ruekert e } \\
\text { Walker (2002); } \\
\text { Song; Noh (2006) }\end{array}$ & $\begin{array}{l}\text { É importante para administrar a integração do time do projeto, revisar e avaliar os projetos } \\
\text { e as respectivas metas, criar motivações e incentivos durante o curso do PDP e, o mais } \\
\text { importante, tomar decisões nos momentos de incerteza. }\end{array}$ \\
\hline $\begin{array}{l}\text { Estratégia } \\
\text { no PDP }\end{array}$ & $\begin{array}{l}\text { Shane; Ulrich (2004); } \\
\text { Griffin (1997); } \\
\text { Krishnan; Loch (2005); } \\
\text { Cheng (2000); } \\
\text { Cormican; O’Sullivan } \\
\quad \text { (2004) }\end{array}$ & $\begin{array}{l}\text { Agrega dois mecanismos: (i) o desenvolvimento de objetivos e metas, no qual a empresa } \\
\text { traduz sua estratégia empresarial em exigências específicas para organização do PDP em } \\
\text { termos de desempenho, como lead time, produtividade e número de novos produtos criados; } \\
\text { (ii) o plano de projeto agregado, que determina o mix específico para tipos de projetos que se } \\
\text { ajusta à estratégia empresarial e afere sua capacidade para empreender aqueles projetos, além } \\
\text { de definir o grupo apropriado de projetos dadas suas oportunidades e restrições. }\end{array}$ \\
\hline $\begin{array}{l}\text { Evitar perda de } \\
\text { conhecimento } \\
\text { no PDP }\end{array}$ & $\begin{array}{l}\text { Antoni, Nilsson-Witell e } \\
\text { Dahlgaard (2005) }\end{array}$ & $\begin{array}{l}\text { Evitar perda de informações tecnológicas obtidas por meio da experiência, seja fazendo testes } \\
\text { nos processos produtivos ou desenvolvendo produtos na área para aprender com eles. Pois, } \\
\text { durante o projeto do processo são tomadas várias decisões que devem ser documentadas para } \\
\text { que não se incorram em erros semelhantes aos ocorridos no passado. }\end{array}$ \\
\hline $\begin{array}{l}\text { Fatores } \\
\text { de sucesso } \\
\text { no PDP }\end{array}$ & $\begin{array}{l}\text { Ozer (2006); Huang (2002); } \\
\text { Lester (1998); Cooper; } \\
\text { Kleinschmidt (2000); } \\
\text { Song; Noh (2006); } \\
\text { Cheng (2000); Cormican; } \\
\text { O'Sullivan (2004) }\end{array}$ & $\begin{array}{l}0 \text { produto deve ser diferenciado proporcionando benefícios ao cliente; ter orientação para } \\
\text { um mercado atrativo; dedicar mais tempo à fase de pré-desenvolvimento; definir bem o } \\
\text { produto e seus conceitos; ter velocidade para lançar o novo produto; e as companhias de } \\
\text { melhor desempenho têm o desenvolvimento de produto estruturado em fases. }\end{array}$ \\
\hline $\begin{array}{l}\text { Gerenciamento } \\
\text { de projetos }\end{array}$ & $\begin{array}{l}\text { Kenny (2003); Thieme, } \\
\text { Song e Shin (2003); Valeri } \\
\text { (2000); Van Oorschot, } \\
\text { Bertrand e Rutte (2005); } \\
\text { Huang (2002); Nambisan } \\
\text { (2003); Lester (1998); } \\
\text { Tonioli (2003); Cooper; } \\
\text { Kleinschmidt (2000); } \\
\text { Cormican; O'Sullivan } \\
\text { (2004) }\end{array}$ & $\begin{array}{l}\text { Oferece uma visão integrada de todos os fatores envolvidos em um projeto para que sejam } \\
\text { atingidos os objetivos assumidos, tendo um enfoque humanístico e participativo, orientado } \\
\text { para a obtenção de resultados, com a premissa de que os resultados são atingidos por meio } \\
\text { do trabalho de pessoas. }\end{array}$ \\
\hline Gestão do PDP & $\begin{array}{l}\text { Da Silva; Alliprandini } \\
\text { (2000); Cheng (2000); } \\
\text { Haque (2003) }\end{array}$ & $\begin{array}{l}\text { A gestão do PDP é complexa, porém são muitas as vantagens competitivas que se obtêm } \\
\text { tendo cada fase bem estruturada e gerenciada entre elas: melhor qualidade do produto, } \\
\text { tempo de lançamento no mercado e manufaturabilidade. }\end{array}$ \\
\hline $\begin{array}{l}\text { Indicadores de } \\
\text { desempenho }\end{array}$ & $\begin{array}{l}\text { Freitas (2004); } \\
\text { Silva (2002) }\end{array}$ & $\begin{array}{l}\text { Os indicadores de desempenho utilizados no projeto do processo estão estruturados de } \\
\text { forma a garantir uma associação imediata com problemas críticos e deve permitir uma } \\
\text { comparação com resultados de outros projetos da empresa e de concorrentes e, também, } \\
\text { com os objetivos e metas estabelecidos, visando o desdobramento de ações de melhoria e } \\
\text { solução de problemas. }\end{array}$ \\
\hline
\end{tabular}


Quadro 1. Continuação...

\begin{tabular}{|c|c|c|}
\hline $\begin{array}{l}\text { Principais } \\
\text { tópicos }\end{array}$ & Referências selecionadas & Abordagem \\
\hline $\begin{array}{l}\text { Inovação } \\
\text { tecnológica para } \\
\text { PDP }\end{array}$ & $\begin{array}{l}\text { Shane; Ulrich (2004); } \\
\text { Lager (2002); Krishnan; } \\
\text { Loch (2005); Nobelius } \\
\text { (2004); Haque (2003) }\end{array}$ & $\begin{array}{l}0 \text { processo de inovação consiste em sua essência na busca, descoberta, experimentação, } \\
\text { desenvolvimento e adoção de novos produtos ou processos produtivos. }\end{array}$ \\
\hline $\begin{array}{l}\text { Integração do } \\
\text { PDP }\end{array}$ & $\begin{array}{c}\text { Abdomerovic; Blakemore } \\
\text { (2002); Amaral (2002); } \\
\text { Freitas (2004); Krishnan; } \\
\text { Loch (2005); Cheng (2000); } \\
\text { Haque (2003) }\end{array}$ & $\begin{array}{l}\text { Integrar é obter uma operação mais eficaz dos processos de negócio de uma empresa e entre } \\
\text { eles, compreendendo as pessoas, máquinas e informação, de acordo com os objetivos da } \\
\text { empresa. }\end{array}$ \\
\hline $\begin{array}{l}\text { Interação das } \\
\text { variáveis de } \\
\text { processo }\end{array}$ & $\begin{array}{l}\text { Abdomerovic; } \\
\text { Blakemore (2002) }\end{array}$ & $\begin{array}{l}\text { Consiste em ter uma visão comum de todas as atividades do processo e suas variáveis, e } \\
\text { compartilhar informações e recursos para obter melhores resultados. }\end{array}$ \\
\hline $\begin{array}{l}\text { Mecanismo de } \\
\text { controle da alta } \\
\text { gerência para } \\
\text { o PDP }\end{array}$ & $\begin{array}{l}\text { Bonner, Ruekert e Walker } \\
\text { (2002); Lester (1998) }\end{array}$ & $\begin{array}{l}\text { A alta gerência pode utilizar indicadores de desempenho para acompanhar os resultados do } \\
\text { desenvolvimento, além de estruturas referenciais que auxiliam na compreensão do processo. }\end{array}$ \\
\hline $\begin{array}{c}\text { Melhoria } \\
\text { contínua e } \\
\text { performance no } \\
\text { PDP }\end{array}$ & $\begin{array}{l}\text { Dooley; Johnson (2001); } \\
\text { Nilsson-Witell, Antoni e } \\
\text { Dahlgaard (2005); Shane; } \\
\text { Ulrich (2004); Hart (2003) }\end{array}$ & $\begin{array}{l}\text { Toda mudança é uma oportunidade de melhoria e aprendizado. A metodologia de } \\
\text { gerenciamento de melhoria mais utilizada é baseada no ciclo planejar, executar, verificar e } \\
\text { agir corretivamente, mais conhecido como PDCA. }\end{array}$ \\
\hline $\begin{array}{c}\text { Mudanças } \\
\text { organizacionais } \\
\text { no } \\
\text { desenvolvimento } \\
\text { de produtos }\end{array}$ & $\begin{array}{l}\text { Chroneer; Laurell-Stenlund } \\
\text { (2001); Dooley; Johnson } \\
\text { (2001); Kenny (2003) }\end{array}$ & $\begin{array}{l}\text { A mudança organizacional das atividades no PDP se refere à forma como os indivíduos estão } \\
\text { ligados, individualmente ou em grupos, seja formal ou informalmente. As mudanças ocorrem } \\
\text { na forma de realizar essa ligação organizacional, seja por meio do alinhamento de funções } \\
\text { ou de projetos. }\end{array}$ \\
\hline $\begin{array}{l}\text { Necessidade de } \\
\text { padrões claros } \\
\text { no PDP }\end{array}$ & $\begin{array}{l}\text { Abdomerovic; Blakemore } \\
\text { (2002); Haque (2003) }\end{array}$ & $\begin{array}{l}\text { A padronização é o estabelecimento de regras comuns e procedimentos que se aplicam } \\
\text { uniformemente a todos, em quase todas as situações. }\end{array}$ \\
\hline $\begin{array}{l}\text { Planejamento de } \\
\text { processo no PDP }\end{array}$ & Kenny (2003) & $\begin{array}{l}0 \text { planejamento inclui informações sobre as possibilidades técnicas e os requisitos de } \\
\text { produção. Considera-se neste planejamento os investimentos necessários e a viabilidade } \\
\text { econômica. }\end{array}$ \\
\hline $\begin{array}{l}\text { Processos de } \\
\text { projeto e produto } \\
\text { complexos }\end{array}$ & $\begin{array}{l}\text { Estorilio (2003); } \\
\text { Kim; Wilemon (2003); } \\
\text { Griffin (1997); Cooper; } \\
\text { Kleinschmidt (2000) }\end{array}$ & $\begin{array}{l}\text { Diferentes combinações da complexidade do produto e do processo dão origem a diferentes } \\
\text { aspectos no gerenciamento do desenvolvimento de produtos. }\end{array}$ \\
\hline $\begin{array}{c}\text { Product } \\
\text { development } \\
\text { business process }\end{array}$ & $\begin{array}{l}\text { Holmes; } \\
\text { Campbell (2002) }\end{array}$ & $\begin{array}{l}\text { Foca o cliente final, integrando diferentes pessoas e áreas funcionais envolvidas e busca uma } \\
\text { simultaneidade na realização das tarefas, para integrar os processos do negócio da empresa. }\end{array}$ \\
\hline $\begin{array}{l}\text { Produtividade do } \\
\text { time no PDP }\end{array}$ & $\begin{array}{l}\text { Syamil, Dol e } \\
\text { Apigian (2004) }\end{array}$ & $\begin{array}{l}\text { A produtividade do time está diretamente relacionada às condições fornecidas pelos gerentes } \\
\text { de projeto e aos resultados conseguidos com o desenvolvimento. }\end{array}$ \\
\hline $\begin{array}{l}\text { Sistema de } \\
\text { informação no } \\
\text { PDP }\end{array}$ & $\begin{array}{l}\text { Nambisan (2003); } \\
\text { Tonioli (2003); Cooper; } \\
\text { Kleinschmidt (2000) }\end{array}$ & $\begin{array}{l}\text { É utilizada como ferramenta de apoio, facilitando a manipulação dos dados para o emprego } \\
\text { de técnicas e métodos disponíveis na área, sua principal vantagem é a velocidade de } \\
\text { processamento e análise de dados, facilitando a geração de relatórios. }\end{array}$ \\
\hline $\begin{array}{l}\text { Stage-Gate e } \\
\text { revisão de fases }\end{array}$ & $\begin{array}{l}\text { Valeri (2000); Hart (2003); } \\
\text { O'Connor (1994); } \\
\text { Lint; Pennings (1999) }\end{array}$ & $\begin{array}{l}\text { Processo sistemático para avaliação do final de fase de um projeto de desenvolvimento } \\
\text { de produto. } 0 \text { resultado final esperado é a aprovação do projeto, que indica qual time de } \\
\text { desenvolvimento poderá dar continuidade a uma nova fase de desenvolvimento, seguindo o } \\
\text { procedimento crítico da transição. }\end{array}$ \\
\hline $\begin{array}{l}\text { Times } \\
\text { multifuncionais } \\
\text { no PDP }\end{array}$ & $\begin{array}{l}\text { Fredericks (2005); Bonner, } \\
\text { Ruekert e Walker (2002); } \\
\text { Griffin (1997); Song; Noh } \\
\text { (2006); Nobelius (2004) }\end{array}$ & $\begin{array}{l}\text { É composto por pessoas de diversas áreas (marketing, engenharia do produto e manufatura), } \\
\text { para exatamente poder unir as suas diferentes habilidades. }\end{array}$ \\
\hline $\begin{array}{l}\text { Tomada de } \\
\text { decisão no PDP }\end{array}$ & $\begin{array}{l}\text { Shane; Ulrich (2004); Hart } \\
\text { (2003); Lint; Pennings } \\
\text { (1999); Krishnan; } \\
\text { Ulrich (2001); Cooper; } \\
\text { Kleinschmidt (2000) }\end{array}$ & $\begin{array}{l}0 \text { desenvolvimento de produtos envolve um grande número de decisões num ambiente de } \\
\text { alta incerteza. Devido a sua natureza complexa, muitas decisões são afetadas por estágios } \\
\text { anteriores e, também, por estágios futuros causando problemas de custo, tempo e qualidade. }\end{array}$ \\
\hline $\begin{array}{l}\text { Trabalho de } \\
\text { equipe no PDP }\end{array}$ & $\begin{array}{l}\text { Syamil, Dol e } \\
\text { Apigian (2004) }\end{array}$ & $\begin{array}{l}\text { Ao longo do PDP é importante que se busque o trabalho em equipe, de forma que as partes } \\
\text { envolvidas percebam que suas contribuições individuais se encaixam em um todo maior, dado } \\
\text { pelo esforço conjunto da equipe. }\end{array}$ \\
\hline $\begin{array}{l}\text { Utilização de } \\
\text { ferramentas } \\
\text { estatísticas no } \\
\text { PDP }\end{array}$ & $\begin{array}{c}\text { Thia (2005); } \\
\text { Larsen; Kim (2001) }\end{array}$ & $\begin{array}{l}\text { A utilização de ferramentas permite que ocorra interação e serve de suporte na condução do } \\
\text { desenvolvimento, considerando que sua escolha depende do tipo de produto e processo a ser } \\
\text { desenvolvido e da estruturação da empresa. }\end{array}$ \\
\hline
\end{tabular}


estudo, justificando então a adoção da abordagem de estudo de caso, que se mostra também como sendo a mais adequada a partir das características apresentadas.

É importante utilizar múltiplas fontes para coleta de dados para obtenção de resultados mais robustos (EISENHARDT, 1989). Portanto, para operacionalizar as escolhas metodológicas feitas neste trabalho, são empregados os seguintes instrumentos de coleta de dados: análise documental, questionários, entrevistas semiestruturadas, e observação direta. No que se refere à análise dos dados, o uso de diversas fontes de evidência permite a utilização da técnica de triangulação, que compreende uma interação entre diversas fontes de evidência para sustentar elementos conceituais importantes da literatura, visando analisar a convergência das fontes de evidência (CAUCHICK MIGUEL, 2007). As seguintes etapas correspondem à condução do estudo de caso:

- Análise documental dos procedimentos operacionais, por meio da leitura de relatórios executivos que contêm o status dos projetos em andamento, atas de reuniões e documentos complementares do PDP, que possuem informações sobre a condução dos projetos de novos produtos, os investimentos com inovação e os tipos de inovação realizados pela empresa;

- Elaboração e aplicação de um questionário direcionado à área de engenharia do produto para compreensão do PDP, baseado na estrutura composta pelas seis dimensões de Clark e Wheelwright (1992): i) definição de projeto; ii) organização do projeto; iii) liderança e gerenciamento de projetos; iv) resolução de problemas; v) teste e protótipos; vi) revisão de gerência e controle, e correções. Complementarmente, utilizou-se ainda três categorias de análise, como na proposta de Zancul, Marx e Metzker (2006): i) estrutura organizacional; ii) papéis, responsabilidades e autonomia; e iii) mecanismos de integração interfuncional;

- Elaboração e aplicação de um questionário com uma definição dos tópicos identificados no referencial teórico do Quadro 1 para compreensão dos conceitos analisados. Este questionário foi aplicado a três engenheiros que coordenam as tarefas de PDP, com experiência superior a 10 anos, oriundos das áreas funcionais de marketing, engenharia do produto e manufatura. Esta coleta de dados ocorreu sem a presença do pesquisador e teve como objetivo avaliar o grau de importância de cada tópico do PDP;

- Realização de uma entrevista semiestruturada com o superintendente de engenharia do produto, que é responsável pelo projeto do processo no PDP da empresa (duração de duas horas), buscando mais informações e esclarecimentos sobre o PDP;
- Elaboração de um questionário específico para compreensão do projeto do processo de produção e seus elementos conceituais importantes. Foram considerados para a elaboração deste questionário: a análise documental apontada anteriormente (item 1); o questionário para compreensão do PDP (item 2); os elementos conceituais do referencial teórico avaliados como mais importantes pelas áreas de marketing, engenharia do produto e manufatura (item 3); e as informações obtidas através de entrevista semiestruturada com o superintendente de engenharia de produto (item 4). Este questionário específico foi aplicado às áreas envolvidas no projeto de processo de produção, uma das fases do PDP;

- Realização de uma segunda entrevista semiestruturada com o superintendente de engenharia de produto, após o retorno das respostas dos questionários específicos à fase de projeto do processo de produção, visando esclarecer eventuais imprecisões e verificar o alinhamento dos conceitos nos níveis hierárquicos da empresa;

- Na análise dos dados, utilizou-se da técnica de triangulação das informações coletadas para identificar convergências e divergências entre as evidências e, em paralelo, comparar os resultados com a literatura. Além disso, por meio da análise cruzada buscou-se também comparar as respostas entre os questionários aplicados às diferentes áreas envolvidas no PDP (marketing, engenharia do produto e manufatura).

\section{Apresentação e discussão dos resultados}

0 principal critério da escolha da empresa é a identificação de que ela possui um PDP estruturado e documentado de acordo com as exigências normativas, como a ISO TS 16949 (ASSOCIAÇÃO..., 2002). Os requisitos normativos do elemento 7.3 da referida norma incluem o projeto e desenvolvimento de produto e projeto do processo de produção. Outros critérios para a escolha do objeto de análise são: a facilidade no acesso às informações, devido a um dos autores atuar no setor siderúrgico, e também os investimentos feitos pela empresa, identificados na análise documental, da ordem de R\$ 32 milhões em P\&D. A empresa é de grande porte, gera 5.487 empregos diretos e aproximadamente 10.000 empregos indiretos, com uma receita líquida de $\mathrm{R} \$ 5,3$ bilhões. Dessa forma, justifica-se também a importância da organização investigada no contexto industrial do País e no setor siderúrgico.

A empresa investigada integra o maior complexo siderúrgico da América Latina, apresentando crescimento positivo de produção há quatro décadas. 
Apresenta uma capacidade de produção de 4,5 milhões de $t$ de aço/ano, fornecendo aços planos para mercados estratégicos da indústria nacional, tais como o automobilístico, naval e de fabricação de tubos. A empresa também tem contratos de cooperação técnica com centros de pesquisa e com usinas siderúrgicas do Japão, tendo conquistado reconhecimentos importantes tais como: o selo Japanese Industrial Standard (JIS), fornecido pelo Ministério da Indústria do Japão na garantia da qualidade e controle estatístico para chapas grossas; Q1 da Ford, que habilitou a empresa a ser fornecedora mundial dessa montadora; além da certificação ISO 9001 (ASSOCIAÇÃO..., 2000).

$\mathrm{Na}$ descrição dos resultados, estes são divididos em duas partes: a primeira é direcionada para o diagnóstico da estrutura do PDP da empresa analisada. Esse diagnóstico teve como base as seis dimensões da estrutura teórica proposta por Clark e Wheelwright (1992) e também nas três categorias de análise de Zancul, Marx e Metzker (2006). A segunda parte apresenta uma análise crítica da fase de projeto do processo de produção no PDP, abordando os principais elementos conceituais desta fase e como estes se inter-relacionam e corroboram para o sucesso no PDP.

\subsection{Diagnóstico da estrutura do PDP da empresa investigada}

A empresa tem funcionários envolvidos com o PDP com a seguinte capacitação: doutores (2), mestres (17), graduados (328), e técnicos de nível médio (164). Referente ao desenvolvimento de produtos, a empresa possui uma área de engenharia de produto que é responsável pela condução deste processo. A equipe é composta por 17 funcionários nos cargos de gerente, engenheiros e assistentes técnicos, com as seguintes atribuições: desenvolvimento e adequação de produtos; atendimento de reclamações técnicas, assessoria técnica a clientes; e consultas de produtos não padronizados.

Os principais tipos de projetos desenvolvidos pela empresa são definidos segundo abordagens distintas: "desenvolvimento de um novo produto"; "adequação ao uso"; "melhoria do desempenho de um produto já disponível"; e "projeto de melhoria da qualidade". Tais projetos geralmente requerem menos recursos do que projetos que trazem avanços significativos, pois eles simplesmente melhoram produtos ou processos de produção existentes através de uma extensão na sua aplicação, conforme o que é estabelecido por Clark e Wheelwright (1993). Os motivadores centrais para o desenvolvimento destes projetos são: a estratégia de atuação no segmento em que o cliente está inserido, a busca de aumento das margens de contribuição, e a evolução tecnológica do produto.

Para gerenciar o PDP, a empresa utiliza-se das seguintes medidas de desempenho no PDP: a análise de volume de produto novo fornecido ao mercado; o tempo gasto em cada fase do desenvolvimento; e o tempo real versus tempo planejado. Também considera como medidas de sucesso: o nível de desempenho (produção, vendas e retorno financeiro) do novo produto; as metas de margem bruta de contribuição do novo produto; as metas de faturamento do novo produto lançados; e o percentual de vendas dos novos produtos na receita total.

Os principais métodos e técnicas de suporte ao PDP utilizados pela empresa estudada são: análise de mercado; análise de risco e potencial de falhas; análise de viabilidade técnica e econômica; análise de custo de fabricação; análise dos modos e efeitos das falhas (FMEA); e técnicas estatísticas e metalúrgicas.

A empresa desenvolveu oito projetos de novos produtos nos dois últimos anos relativos à condução do presente trabalho. Três destes encontravam-se em andamento, dois foram suspensos e três concluídos e lançados no mercado, dentre estes um no setor metalúrgico (chapas grossas na qualidade $\mathrm{API}$ - American Petroleum Institute) e dois no setor de construção civil (aços com qualidade soldável de alta resistência para estruturas). 0 tempo de desenvolvimento de um novo produto varia conforme sua complexidade e importância estratégica para empresa. Em média, os três projetos concluídos neste período tiveram uma duração de dois anos. Em três anos, a empresa forneceu ao mercado aproximadamente $50 \mathrm{mil} \mathrm{t}$ de aço referentes a produtos novos, que representam um faturamento de $R \$ 64,5$ milhões, com uma margem bruta de $\mathrm{R} \$ 15,5$ milhões. 0 faturamento com novos produtos significou aproximadamente $1 \%$ da receita líquida da empresa no período.

A partir dessa análise inicial, obteve-se uma visão geral da estrutura organizacional e times de desenvolvimento de novos produtos da empresa. A Figura 2 representa a estrutura organizacional e destaca os níveis hierárquicos e times formados para conduzir o PDP.

A seguir, são detalhadas as seis dimensões de análise de Clark e Wheelwright (1992), conforme a coleta de dados realizada na empresa investigada. Este referencial foi escolhido para o presente trabalho devido ao fato de que a sua abordagem proporciona uma visão sistêmica e integrada do PDP, apresentando uma percepção ampla do processo, de suas interfaces e de cada fase específica do PDP. São ainda consideradas a passagem de fases, gestão dos recursos e complexidade da estrutura organizacional. 


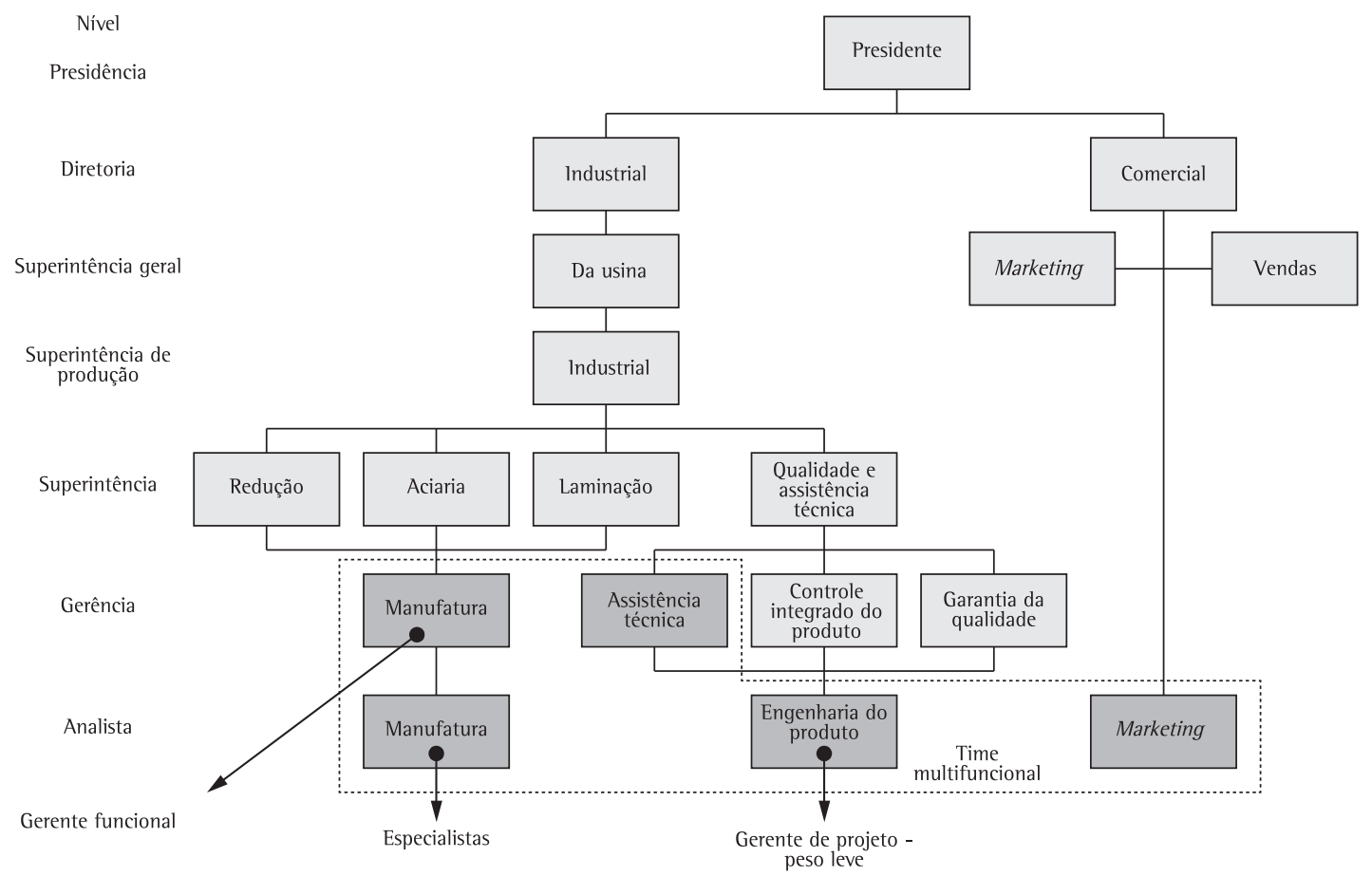

Figura 2. Estrutura organizacional e times do PDP na empresa estudada.

- Definição de projeto:

A área de marketing realiza reuniões periódicas mensais com a área de engenharia do produto para definir, alinhar e priorizar a carteira de desenvolvimento de novos produtos para o próximo ano. Caso ocorra alguma mudança no ambiente de negócios, são realizadas reuniões estratégicas extraordinárias. 1sto não impede que, ao longo do ano, possam surgir projetos prioritários e que levem até a interrupção de algum projeto de novo produto em andamento. As razões que deflagram o desenvolvimento de um novo produto variam e podem ocorrer devido a solicitações de clientes, informações sobre concorrentes, análise de mercado, recomendações de relatórios de pesquisa e informações da literatura. Porém, as razões nos últimos dois anos concentraram-se exclusivamente na análise de mercado.

0 desenvolvimento de um novo produto contempla o enobrecimento de produtos para o mercado interno e exportação crescente de semiacabados. Estes são balanceados de acordo com a estratégia de competitividade da empresa, buscando atender à demanda do mercado. A distribuição dos projetos da empresa por área de negócios encontra-se da seguinte forma: industrial (37\%); exportação (25\%); construção civil (25\%); e linha branca (13\%).

0 PDP da empresa, qualquer que seja a origem da ideia, inicia na área de marketing que deve ser consultada e deve autorizar o desenvolvimento, após uma prospecção de mercado. Para a definição do escopo do projeto, as áreas de marketing e de engenharia do produto definem os projetos de novos produtos que serão desenvolvidos. A seguir, a área de engenharia do produto discute os quesitos tecnológicos com as unidades de manufatura. Se concluir pela inviabilidade do desenvolvimento, informa isto para a área de marketing; se o projeto é viável, programam-se reuniões para discussão dos parâmetros técnicos necessários e redige-se o documento denominado RAE (Relatório de Avaliação de Experiência), no qual se destacam os objetivos do desenvolvimento, as características do pedido, as responsabilidades de cada área e os parâmetros de produção de cada unidade fabril. Definem-se ainda os testes de liberação, testes complementares, e os parâmetros de liberação do material produzido.

- Organização de projeto e pessoal:

A estrutura organizacional do projeto é distribuída da seguinte forma: a área de marketing é a solicitante e coordenadora geral do PDP, a área de engenharia do produto é responsável tecnicamente pelo desenvolvimento do produto e a manufatura faz com que sejam cumpridos os parâmetros de fabricação definidos no RAE. 0 time é multifuncional envolvendo um participante de cada área no PDP (marketing, engenharia do produto e manufatura) e é definido durante a fase de preparação do RAE. Todo projeto 
de novo produto tem um gerente de projeto da área de engenharia do produto, que é responsável pelo planejamento e controle do projeto, elabora o RAE e discute-o com as áreas de manufatura, até que haja um consenso dos parâmetros ali definidos. 0 gerente de projeto também acompanha a condução experiência industrial (testes na produção), analisa os resultados obtidos, efetua alterações, quando necessárias, fornece as informações para as áreas encarregadas da implantação do novo produto nas especificações da empresa e escreve o relatório final de desenvolvimento. No caso da área de manufatura, existe a figura do gerente funcional, que é responsável pela alocação de recursos das áreas e negociação de prazos no portfolio de projetos. Existe o especialista, que possui experiência de cerca de 10 anos, que representa as áreas funcionais nas reuniões de projeto e atua na execução de atividades no PDP. Pode-se ter mais de um gerente funcional e especialista por projeto, conforme os equipamentos da rota de fabricação do novo produto. Estes gerentes são os indivíduos nomeados como responsáveis para o cumprimento dos parâmetros operacionais de suas respectivas áreas. Todos estes participantes podem estar envolvidos em mais de um projeto.

- Liderança e gerenciamento de projeto:

0 gerente de engenharia do produto é o responsável final pelo andamento da experiência industrial, supervisionando os trabalhos do gerente de projeto (da área de engenharia do produto). Os gerentes funcionais supervisionam problemas que podem vir a ocorrer em suas áreas de atuação, em função do desenvolvimento em andamento.
0 PDP está dividido em cinco fases: i) entrada do projeto (solicitação do projeto pela área de marketing); ii) saída do projeto (discussão e emissão do ERA); iii) verificação do projeto (resultados da produção proveniente da experiência industrial); iv) validação do projeto (realização de experiências com o produto nos clientes e/ou confronto dos resultados obtidos com as exigências das normas técnicas internacionais, de clientes ou da própria organização); e v) consolidação do projeto (acompanhamento dos primeiros lotes fabricados contra pedidos de clientes - fase de pré-venda). As revisões são realizadas no final de cada fase (Figura 3) ou quando necessário, isto é, quando os parâmetros definidos no RAE não atendem aos requisitos exigidos para o produto ou quando os processos de manufatura apresentam problemas durante a fabricação do produto.

- Resolução de problemas, testes e protótipos:

Para a resolução de problemas, são utilizadas técnicas estatísticas e metalúrgicas para a interpretação dos resultados obtidos, além do conhecimento teórico e prático do gerente de projeto. Os testes baseiam-se principalmente na oscilação das variáveis de processo conforme as especificações exigidas para o produto. A quantidade e tipos de testes variam de acordo com a criticidade operacional de cada equipamento participante na fabricação do produto. Alguns exemplos de testes são: oscilação na temperatura do forno de reaquecimento das placas, espessura e planicidade de laminação, propriedades mecânicas, adição de ligas, soldagem, acabamento etc. Os testes podem ser realizados dentro do programa de produção e alguns deles também podem ser feitos nos clientes para acompanhamento da performance do produto.

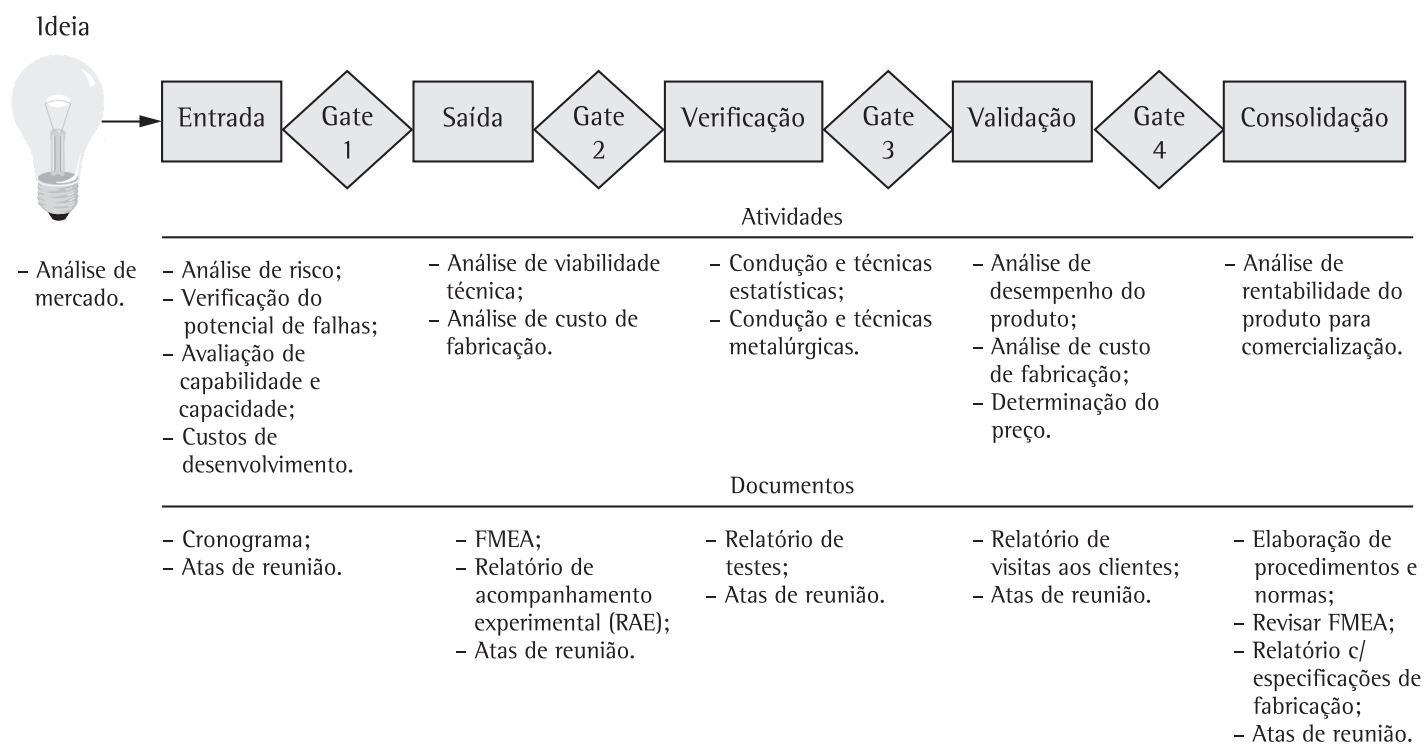

Figura 3. Deliverables de passagem de fase no PDP da empresa estudada. 
- Revisões gerenciais e controle:

As revisões de fase ocorrem sempre ao término de cada fase (Figura 3), sendo obrigatórias para passagem de fase, e avaliam a possibilidade de continuidade do projeto e os riscos envolvidos nesta decisão. Além disso, também podem ser utilizadas revisões intermediárias antes do final de cada fase. Com isso, se ganha tempo no redirecionamento correto do projeto até a revisão de fase, nas seguintes situações: quando há dificuldades operacionais para a obtenção do produto; quando os resultados obtidos não atendem às especificações normativas; ou quando, mesmo atendendo às disposições legais e normativas, há dificuldade de aplicação do produto no cliente. Quando existe a necessidade de uma revisão antes do término da fase, faz-se uma análise crítica na qual são apontados os motivos pelos quais ela será realizada, elabora-se um adendo ao RAE, divulgando-o para todas as áreas envolvidas. Se necessário, elabora-se novo cronograma informando a área comercial que comunicará o cliente sobre os motivos e novos prazos para realização desta fase. A empresa também estabelece quais são as atividades e documentos necessários para passagem de fase.

\section{- Correções de projeto:}

As correções de projeto são realizadas quando existe a necessidade de alterações ou melhoria de resultados, ou ainda quando a experiência não levar aos resultados almejados de especificação técnica. Quando há necessidade, o gerente de projeto formaliza instruções complementares, por meio de uma revisão ou adendo ao RAE, para conhecimento do pessoal envolvido. Estas alterações são discutidas com as áreas envolvidas e é analisada a viabilidade de implementação. Caso necessário, é elaborado novo cronograma de atividades, e as planilhas de FMEA são revistas. Caso ocorra a postergação das atividades e estas comprometam o prazo final de conclusão do projeto, é feita uma análise crítica nos planos e projetos do cliente bem como é avaliada a possível perda mercadológica para a empresa, informando o atraso ao cliente.

Depois de ter compreendido o PDP da empresa estudada, para se fazer uma avaliação da estrutura organizacional da empresa, são utilizadas três categorias de análise, baseadas no trabalho de Zancul, Marx e Metzker (2006): i) estrutura organizacional; ii) papéis (divisão de tarefas), responsabilidades e autonomia; e iii) mecanismos de integração interfuncional.

A estrutura organizacional da empresa varia conforme os tipos de projetos, ou seja, a área de engenharia do produto coordenadora da fase de projeto do processo no PDP é dividida por categoria de produto a ser desenvolvido (chapas grossas, tiras laminadas a quente, tiras laminadas a frio e placas para exportação). A estrutura organizacional se assemelha a de time 'peso leve', no qual o engenheiro da área de engenharia de produto ('gerente peso leve') é responsável pelo andamento da experiência industrial. Entretanto, ele não tem autonomia sobre os processos de desenvolvimento realizados na manufatura. Existem os gerentes de manufatura (gerentes funcionais), que são responsáveis diretos por problemas no PDP que podem vir a ocorrer em suas respectivas áreas de atuação durante o PDP. Quando não se consegue conduzir o projeto conforme planejado, devido a divergências entre os envolvidos no time multifuncional, a discussão sobe de nível gerencial para o nível de superintendência e posteriormente para o de diretoria; não existem registros de que isso tenha ocorrido.

Com relação aos papéis e responsabilidades dos envolvidos no PDP, os conceitos utilizados são equivalentes aos apresentados na literatura. No quesito integração, a empresa adota atividades simultâneas e estrutura de trabalho em times de desenvolvimento. A integração ocorre principalmente por meio de reuniões, comunicações eletrônicas e relatórios de acompanhamento do PDP. Porém, existem alguns fatores que podem prejudicar a integração, uma vez que cada área funcional possui diferentes prioridades.

Em suma, a adoção de estrutura matricial "peso leve' e a utilização de times multifuncionais no PDP pela empresa implicam em algumas vantagens diferenciais tais como: melhorias nos canais de comunicação, maior difusão das informações, melhoria da cooperação e dos relacionamentos interfuncionais. Foi possível identificar que tais características contribuem significativamente para a redução do tempo de desenvolvimento de produto, como também para ajustes no processo em virtude das alterações no mercado e ações da concorrência e de restrições operacionais.

\subsection{Análise da fase de projeto do processo de produção no PDP da empresa investigada}

Esta seção busca compreender como a empresa analisada conduz a fase de projeto do processo de produção e verificar o entendimento das áreas envolvidas sobre a importância dos elementos conceituais identificados no referencial teórico. Para definir o recorte de análise neste trabalho, foi elaborada uma tabela de priorização para avaliar a importância de cada elemento conceitual no PDP na empresa investigada. 
0 Quadro 1, apresenta os 32 elementos conceituais importantes no PDP a partir da análise da literatura, enquanto que a Tabela 1 apresenta os 12 tópicos melhor avaliados em termos de importância na empresa investigada. Esta avaliação de importância foi feita por meio da aplicação de um questionário nas áreas envolvidas com o PDP. 0 critério de pontuação da tabela foi adaptado da escala usada no método QFD (desdobramento da função qualidade) para determinar as relações de intensidade nas matrizes: 0-nenhuma relação; 1-baixa relação; 3-média relação; e 9-alta relação. A atribuição de cada elemento conceitual foi feita por profissionais das áreas de marketing, engenharia de produto e manufatura, que avaliaram cada um deles (mostrados no Quadro 1), indicando a sua importância para cada fase do PDP da empresa investigada (desenvolvimento do conceito, planejamento do produto, engenharia do produto/ processo, e produção piloto/aumento da produção). $\mathrm{Na}$ sequência foi feita uma somatória dos pontos atribuídos em cada fase (0, 1, 3 ou 9), para cada elemento conceitual. Foram então selecionados os elementos conceituais com a maior pontuação obtida, listados na Tabela 1 (a tabela mostra aqueles que obtiveram um total superior a 80 pontos), sendo considerados como os mais importantes pelas áreas envolvidas no PDP.
No entanto, como o trabalho tem como um dos seus objetivos a avaliação da fase de projeto do processo de produção, optou-se por analisar somente os elementos conceituais avaliados como mais importantes para esta fase do PDP, e não a somatória de todas as quatro fases (que representa a importância dos tópicos para o PDP como um todo). Assim, foram selecionados os tópicos que receberam maior pontuação nas fases de engenharia do produto/ processo e produção piloto/aumento da produção, descartando os pontos obtidos nas fases iniciais de desenvolvimento do conceito e planejamento do produto. A Tabela 2 lista os 10 elementos conceituais mais bem avaliados no projeto do processo de produção, com um corte em 46 pontos, que representa pouco mais de $85 \%$ dos 54 pontos totais possíveis. Para definir o ponto de corte, foram adotados os mesmos critérios anteriormente descritos.

Os elementos conceituais citados na Tabela 2 serviram de base para elaboração de outro questionário, com o objetivo de analisar em mais detalhes como estes elementos conceituais se relacionam e influenciam a fase de projeto do processo de produção no PDP da empresa. Esse questionário foi elaborado com perguntas abertas sobre os 12 elementos conceituais (Tabela 2), o que auxiliou na obtenção de dados mais detalhados dos

Tabela 1. Principais elementos conceituais relacionados ao PDP na visão das áreas funcionais.

\begin{tabular}{|c|c|c|c|c|}
\hline Principais tópicos & Marketing & Eng. do produto & Manufatura & Total \\
\hline Trabalho de equipe & 36 & 36 & 36 & 108 \\
\hline Colaboração e comunicação & 36 & 30 & 36 & 102 \\
\hline Aprendizagem do time & 36 & 24 & 36 & 96 \\
\hline Entender os problemas das áreas envolvidas & 36 & 30 & 30 & 96 \\
\hline Necessidade de padrões claros & 36 & 24 & 36 & 96 \\
\hline Produtividade do time & 36 & 30 & 28 & 94 \\
\hline Fatores de sucesso & 36 & 16 & 36 & 88 \\
\hline Melhoria contínua e performance & 36 & 22 & 30 & 88 \\
\hline Sistema de informação & 36 & 30 & 22 & 88 \\
\hline Duração do ciclo de desenvolvimento de produtos & 36 & 24 & 20 & 80 \\
\hline Envolvimento da alta gerência & 36 & 30 & 14 & 80 \\
\hline Gestão do PDP & 36 & 16 & 28 & 80 \\
\hline
\end{tabular}

Tabela 2. Principais elementos conceituais associados ao projeto do processo de produção.

\begin{tabular}{|c|c|c|c|c|}
\hline Principais tópicos & Marketing & Eng. do produto & Manufatura & Total \\
\hline Trabalho de equipe no PDP & 18 & 18 & 18 & 54 \\
\hline Colaboração e comunicação no PDP & 18 & 18 & 18 & 54 \\
\hline Aprendizagem do time no PDP & 18 & 12 & 18 & 48 \\
\hline Entender os problemas das áreas envolvidas & 18 & 18 & 12 & 48 \\
\hline Inovação tecnológica para PDP & 18 & 12 & 18 & 48 \\
\hline Interação das variáveis de processo & 18 & 18 & 12 & 48 \\
\hline Necessidade de padrões claros no PDP & 18 & 12 & 18 & 48 \\
\hline Produtividade do time no PDP & 18 & 12 & 18 & 48 \\
\hline Melhoria contínua e performance no PDP & 18 & 10 & 18 & 46 \\
\hline Sistema de informação no PDP & 18 & 18 & 10 & 46 \\
\hline
\end{tabular}


respondentes. As perguntas do questionário abordam os seguintes temas: integração interfuncional do time de desenvolvimento; comunicação entre as equipes; controle da produtividade do time de desenvolvimento; existência de práticas de melhoria contínua e de aprendizagem; identificação da influência da inovação tecnológica no processo; auxílio do sistema de informação no processamento de dados; e existência de procedimentos claros de condução do PDP. A partir de uma análise dos dados obtidos com a aplicação do questionário, a Quadro 2 apresenta uma síntese das principais relações e influências dos tópicos com a fase de projeto do processo na empresa investigada.

A análise das relações e influências dos tópicos do projeto do processo de produção demonstra que existe uma convergência da importância desses elementos conceituais para melhorar o trabalho em equipe nesta fase do PDP. lsto pode ser justificado devido às características do processo siderúrgico, envolvendo grandes equipamentos (altos-fornos, aciaria, laminadores etc.), que trabalham de forma sequencial e integrada em uma relação de fornecedor e cliente. Aparentemente, esta relação facilita a integração interfuncional e o entendimento das limitações das áreas envolvidas no projeto do processo no PDP.

No elemento conceitual 'colaboração e comunicação', identifica-se uma maior facilidade na troca de informações na organização, que gera agilidade no entendimento e solução de problemas operacionais, durante o experimento industrial do novo produto. Esta maior facilidade está relacionada à utilização de algumas práticas comuns, porém importantes, de realizar reuniões periódicas de análise crítica, acompanhar in loco o desenvolvimento do experimento e verificar o desempenho dos projetos de novos produtos via relatórios.

Para o elemento conceitual "padrões claros e aprendizagem do time na fase de projeto do processo no PDP', a empresa analisada é beneficiada pela característica do setor siderúrgico de possuir os seus

Quadro 2. Análise da influência dos tópicos da fase de projeto do processo no PDP da empresa estudada.

\begin{tabular}{|c|c|c|}
\hline $\begin{array}{l}\text { Principais } \\
\text { tópicos }\end{array}$ & Literatura & Empresa estudada \\
\hline $\begin{array}{l}\text { Trabalho } \\
\text { de equipe } \\
\text { no PDP }\end{array}$ & $\begin{array}{l}\text { Ao longo do PDP é importante que se busque o trabalho em } \\
\text { equipe, de forma que as partes envolvidas percebam que suas } \\
\text { contribuições individuais se encaixam em um todo maior, dado } \\
\text { pelo esforço conjunto da equipe. }\end{array}$ & Formação de time multifuncional de desenvolvimento. \\
\hline $\begin{array}{l}\text { Colaboração } \\
\text { e comunicação } \\
\text { no PDP }\end{array}$ & $\begin{array}{l}\text { A comunicação refere-se à troca de informações, valendo } \\
\text { para os tipos verbais e escritos. A colaboração diferencia-se da } \\
\text { comunicação devido ao foco em aspectos como trabalho em } \\
\text { grupo, compartilhamento de recursos, confiança mútua, e objetivo } \\
\text { e visão comuns, ou seja, aspectos mais informais e subjetivos. }\end{array}$ & $\begin{array}{l}\text { Comunicação por meio de reuniões periódicas; } \\
\text { comunicações eletrônicas; e relatório de acompanhamento } \\
\text { do PDP. }\end{array}$ \\
\hline $\begin{array}{l}\text { Aprendizagem do } \\
\text { time no PDP }\end{array}$ & $\begin{array}{l}\text { A aprendizagem se dá principalmente pela troca de informações } \\
\text { obtidas por meio da experiência no PDP, e o mais importante é } \\
\text { não se esquecer de documentá-las. }\end{array}$ & $\begin{array}{l}\text { Toda documentação do PDP é arquivada; divulgação de } \\
\text { resultados via relatório. Novas atividades são padronizadas } \\
\text { e, em seguida, o pessoal envolvido é treinado. }\end{array}$ \\
\hline $\begin{array}{l}\text { Entender os } \\
\text { problemas das } \\
\text { áreas envolvidas } \\
\text { no PDP }\end{array}$ & $\begin{array}{l}\text { Através da integração, buscar entender as limitações e variáveis } \\
\text { de processo envolvidas no PDP. }\end{array}$ & $\begin{array}{l}\text { Reuniões entre os especialistas das áreas que expõem as } \\
\text { restrições de processo de seu equipamento. }\end{array}$ \\
\hline $\begin{array}{l}\text { lnovação } \\
\text { tecnológica }\end{array}$ & $\begin{array}{l}\text { A inovação tecnológica consiste na busca de novos produtos ou } \\
\text { novos processos produtivos. }\end{array}$ & $\begin{array}{l}\text { Um fator limitante na fase de projeto de processo é o } \\
\text { estado tecnológico dos equipamentos, que restringem a } \\
\text { fabricação de determinados produtos. }\end{array}$ \\
\hline $\begin{array}{l}\text { Interação das } \\
\text { variáveis de } \\
\text { processo }\end{array}$ & $\begin{array}{l}\text { Consiste na visão de todas as atividades do processo e suas } \\
\text { variáveis, e compartilhar informações e recursos para melhores } \\
\text { resultados. }\end{array}$ & $\begin{array}{l}\text { Existência de muitos equipamentos diferentes, que } \\
\text { necessitam de conhecimentos específicos. A decorrência é } \\
\text { a necessidade dos especialistas participarem das reuniões } \\
\text { e exporem seu conhecimento. }\end{array}$ \\
\hline $\begin{array}{l}\text { Necessidade de } \\
\text { padrões claros } \\
\text { no PDP }\end{array}$ & $\begin{array}{l}\text { A padronização é o estabelecimento de regras comuns e } \\
\text { procedimentos que se aplicam uniformemente a todos, em } \\
\text { quase todas as situações. }\end{array}$ & $\begin{array}{l}\text { Existência de normas de qualidade e documentos } \\
\text { complementares que detalham os procedimentos do PDP. }\end{array}$ \\
\hline $\begin{array}{l}\text { Produtividade do } \\
\text { time no PDP }\end{array}$ & $\begin{array}{l}\text { A produtividade do time está diretamente relacionada às } \\
\text { condições fornecidas pelos gerentes de projeto e aos resultados } \\
\text { conseguidos com o PDP. }\end{array}$ & $\begin{array}{l}0 \text { acompanhamento do produto com as seguintes } \\
\text { exigências do time de desenvolvimento: resultados } \\
\text { técnicos, custo do produto, cumprimento de prazos. }\end{array}$ \\
\hline $\begin{array}{l}\text { Melhoria } \\
\text { contínua e } \\
\text { performance } \\
\text { no PDP }\end{array}$ & $\begin{array}{l}\text { Toda mudança é uma oportunidade de melhoria e aprendizado, } \\
\text { a metodologia de gerenciamento de melhoria mais utilizada } \\
\text { é baseada no ciclo planejar, executar, verificar e agir } \\
\text { corretivamente (ciclo PDCA). }\end{array}$ & $\begin{array}{l}\text { Utilização do ciclo PDCA; monitoramento da performance } \\
\text { do produto fazendo ajustes. }\end{array}$ \\
\hline $\begin{array}{l}\text { Sistema de } \\
\text { informação } \\
\text { no PDP }\end{array}$ & $\begin{array}{l}\text { Utilização como ferramenta de apoio, facilitando a manipulação } \\
\text { dos dados para o emprego de técnicas e métodos disponiveis } \\
\text { na área. A principal vantagem é a velocidade de processamento } \\
\text { e análise de dados, facilitando a geração de relatórios. }\end{array}$ & $\begin{array}{l}\text { Existência de banco de dados no 'Sistema de automação } \\
\text { de produção' e uso de ferramentas estatísticas. }\end{array}$ \\
\hline
\end{tabular}


procedimentos normalizados, a partir da constante manutenção das certificações de qualidade, que documentam as atividades relacionadas ao PDP e exigem o treinamento das pessoas envolvidas a cada modificação nos procedimentos.

Além disso, dois fatos merecem ser destacados na fase de projeto do processo de produção, com base nas boas práticas existentes na empresa investigada. 0 primeiro fato é que, devido às atribuições da alta gerência de tomar decisões e solucionar problemas de interface organizacional no PDP, nunca houve necessidade de se interferir no andamento desta fase, pois o próprio gerente de projeto 'peso leve' soluciona os problemas junto ao time de desenvolvimento. 0 segundo fato é referente às práticas de melhoria contínua no projeto do processo de produção. As práticas de melhoria ocorrem de duas maneiras: quando acontecem dificuldades organizacionais durante esta fase, que podem causar atrasos ou impedimentos ao andamento do processo ou quando o novo produto é implantado. No caso dessa última, ao monitorar o seu desempenho e constatar irregularidades, imediatamente são feitos ajustes de conformidade e de rendimento.
Em resumo, pelo fato de a empresa ter a gestão da fase de projeto do processo de produção no PDP auxiliado por sistemas informatizados, ferramentas de suporte, e normas de qualidade, consegue um melhor acompanhamento desta fase pela alta gerência, propiciando a tomada de decisões em conjunto com a equipe de projeto de maneira mais precisa.

Um elemento conceitual considerado crítico na fase de projeto do processo de produção no setor siderúrgico é o 'grau de inovação tecnológica', que consiste na capacidade da empresa em desenvolver novos produtos e/ou processos de produção, decorrentes da incorporação de novas tecnologias. 0 estado tecnológico dos equipamentos pode limitar a fabricação de determinados produtos, devido às exigências, cada vez maiores, das especificações dos clientes. Contudo, observa-se que há um acúmulo de competências tecnológicas, quanto à capacidade de introduzir mudanças técnicas incrementais nos processos de fabricação/produção, desenvolvimento de novos produtos e melhoria do desempenho dos equipamentos.

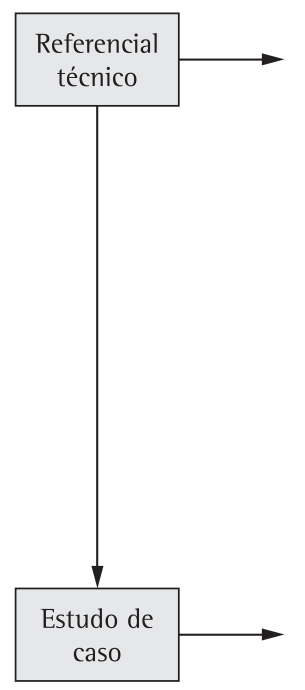

1. Varredura horizontal no PDP

- Processo de desenvolvimento de produtos;

- Classificação de projetos conforme o grau de inovação tecnológica;

- Estrutura referencial para gerenciamento do PDP;

- Impacto da complexidade do produto e projeto no PDP

- Indicadores de desempenho e medidas de sucesso no PDP;

- Integração interfuncional no PDP;

- Métodos de suporte ao PDP;

- Arranjos organizacionais e papéis das pessoas envolvidadas no PDP.

2. Varredura vertical no projeto de processo

3. Identificação dos tópicos relacionados ao PDP

4. Análise documental

5. Compreensão do PDP (CLARK; WHEEL WRIGHT, 1992)

- Definição do projeto;

- Organização do projeto;

- Liderança e gerenciamento de projetos;

- Resolução de problemas, teste e protótipos;

- Revisão de gerência e controle;

- Correções.

6. Análise da estrutura organizacional (ZANCUL; MARX; METZKER, 2006)

- Estrutura organizacional;

- Papéis (divisão de tarefas), responsabilidades e autonomia;

- Mecanismos de integração interfuncional.

7. Avaliação dos tópicos relacionados ao PDP por fase

- Todas as fases do PDP, desenvolvimento do conceito, planejamento do produto, engenharia do produto processo, e produção piloto/aumento da produção.

8. Identificação dos tópicos relacionandos ao projeto do processo

- Fase de projeto do processo, engenharia do produto/processo e produção piloto/aumento da produção.

9. Análise dos tópicos relacionados ao projeto do processo

Figura 4. Proposta de diagnóstico dos tópicos relacionados ao projeto do processo de produção no PDP. 
A partir desse trabalho, enfatiza-se a importância da fase de projeto do processo de produção no PDP, principalmente em empresas que possuem várias interfaces organizacionais e complexidade operacional. Com base no trabalho de campo, o presente trabalho sugere uma proposta para diagnóstico dos elementos conceituais que influenciam no 'projeto do processo de produção no PDP'. Esta proposta é esboçada na Figura 4, na expectativa de direcionar o desenvolvimento de trabalhos empíricos futuros, visando expandir a validade externa (grau de generalização) do presente trabalho.

\section{Conclusões}

A partir da análise dos resultados do trabalho empírico, considera-se ter atingido os objetivos do presente trabalho, obtendo-se uma caracterização geral do PDP e avaliando-o com base na literatura e também como a fase de projeto do processo de produção está estruturada. Foi também possível identificar práticas organizacionais, alinhadas à literatura, focando na condução do desenvolvimento industrial do PDP e suas respectivas interfaces organizacionais, neste caso, envolvendo as áreas de marketing, engenharia do produto e manufatura.

Como ponto conclusivo, constata-se que a empresa investigada conduz o projeto do processo de produção no PDP de acordo com a literatura, pois se utiliza de métodos, técnicas e ferramentas de suporte ao PDP que auxiliam na estruturação desta fase. Além destas práticas, vale ressaltar as características de integração interfuncional na empresa que, devido às diferentes áreas envolvidas no projeto do processo, buscam uma comunicação mais eficaz, contando com um gerente de projeto 'peso leve' responsável por coordenar toda a fase operacional e evitar possíveis problemas de comunicação entre as funções envolvidas nesta fase.

Conclui-se também que a organização apresentou baixa intensidade de gastos em P\&D. Isto pode indicar que o setor siderúrgico é maduro em termos tecnológicos. Também foi evidenciado um número relativamente pequeno de novos produtos introduzidos e os resultados financeiros com o PDP são também relativamente baixos, ou seja, inferiores a $1 \%$ da receita líquida. lsso pode refletir o tipo de mercado em que a organização atua, com produtos de menor valor agregado em uma das plantas e com produtos de maior valor agregado na outra planta. No entanto, conclui-se que o desenvolvimento de novos produtos, apesar de ser de baixa intensidade, pode ser considerado estrategicamente importante para que a organização satisfaça às exigências dos clientes e mantenha-se na liderança no segmento de aços planos no mercado interno, possibilitando assim manter mercados importantes e comercializar produtos de última geração para diversos setores nacionais.

\section{Agradecimentos}

Os autores agradecem aos avaliadores do artigo que contribuíram significativamente para sua melhoria e também à empresa que permitiu que este estudo fosse realizado. No entanto, o trabalho reflete a visão dos autores e não da organização investigada. Um dos autores tem vínculo com a Universidade Federal de Santa Catariana e, por esta razão, esta instituição também merece agradecimentos.

\section{Referências}

ABDOMEROVIC, M.; BLAKEMORE, G. Project process interactions. International Journal of Project Management, v. 20, p. 315-323, 2002. http://dx.doi.org/10.1016/S02637863(01)00014-X

AKGUN, A. E.; LYNN, G. S.; BYRNE, J. C. Antecedents and consequences of unlearning in new product development teams. The Journal of Product Innovation Management, v. 23, p. 73-88, 2006. http://dx.doi.org/10.1111/j.15405885.2005.00182.x

ALTAMIRANO, A. V. Metodologia para integração do marketing e da manufatura. 1999. 245 f. Tese (Doutorado em Engenharia de Produção)-Universidade Federal de Santa Catarina, Florianópolis, 1999.

AMARAL, D. C. Arquitetura para gerenciamento de conhecimentos explícitos sobre o processo de desenvolvimento de produto. 229 f. Tese (Doutorado em Engenharia Mecânica)-Universidade Federal de São Carlos, São Carlos, 2002.

ANTONI, M.; NILSSON-WITELL, L.; DAHLGAARD, J. J. Inter-project improvement in product development. International Journal of Quality \& Reliability Management, v. 22, n. 9, p. 876-893, 2005. http://dx.doi. org/10.1108/02656710510625194

ASSOCIAÇÃO BRASILEIRA DE NORMAS TÉCNICAS - ABNT. NBR ISO 9001: Sistema de gestão da qualidade - Requisitos. Rio de Janeiro: ABNT, 2000.

ASSOCIAÇÃO BRASILEIRA DE NORMAS TÉCNICAS - ABNT. NBR ISO TS 16949: Sistema de gestão da qualidade - Requisitos particulares para aplicação da NBR 1SO 9001:2000 para organizações de produção automotiva e peças de reposição pertinentes. Rio de Janeiro: ABNT, 2002.

BARKAN, P. Productivity in process of product development; an engineering perspective. Integrate design and manufacturing for competitive advantage, v. 1, p. 56-58, 1992.

BONNER, J. M.; RUEKERT, R. W.; WALKER, O. C. Upper management control of new product development projects and project performance. The Journal of Product Innovation Management, v. 19, p. 233-245, 2002. http:// dx.doi.org/10.1111/1540-5885.1930233

BSTIELER, L.; GROSS, C. W. Measuring the effect of environmental uncertainty on process activities, project team characteristics, and new product success. The Journal of business \& Industrial Marketing, v. 18, n. 2-3, p. 146161,2003.http://dx.doi.org/10.1108/08858620310463079

CARTER, D. E.; BAKER, B. S. Concurrent engineering: the product development environment for the 1990s. Reading: Addison-Wesley, 1992.

CHENG, L. C. Caracterização da Gestão de Desenvolvimento do Produto: Delineando o seu contorno e dimensões básicas. In: CONGRESSO BRASILEIRO DE GESTÃO DE DESENVOLVIMENTO DE PRODUTO, 2., 2000, São Carlos. Anais... São Carlos: 2000. 
CHRONEER, D.; LAURELL-STENLUND, K. Organizational changes in product development in various process industries. Journal of Engineering and Technology Management, p. 589-598, 2001.

CLARK, K. B.; FUJIMOTO, T. Product development performance: strategy, organization and management in the world auto industry. Boston: Harvard Business School Press, 1991.

CLARK, K. B.; WHEELWRIGHT, S. C. Revolutionizing product development: quantum leaps in speed, efficiency and quality. New York: The Free Press, 1992.

CLARK, K. B.; WHEELWRIGHT, S. C. Managing New Product and Process Development. New York: The Free Press, 1993.

CLAUSING, D. Total quality development: a step-by-step guide to world-class concurrent engineering. New York: ASME Press, 1994. p. 1-172.

COOPER, R. G. Winning at new products: accelerating the process from idea to launch. Reading: Perseus Books, 1993.

COOPER, R. G.; KLEINSCHMIDT, E. J. New product performance: What distinguishes the star products. Australian Journal of Management, v. 25, n. 1, p. 17-25, 2000.

CORMICAN, K.; O'SULLIVAN, D. Auditing best practice for effective product innovation management. Technovation, v. 24, p. 819-829, 2004. http://dx.doi.org/10.1016/S01664972(03)00013-0

DA SILVA, M. M.; ALLIPRANDINI, D. H. Análise do processo de desenvolvimento de produto: estudo de caso em empresas manufatureiras baseado em um modelo referencial para caracterização e diagnóstico. In: CONGRESSO BRASILEIRO DE GESTÃO DE DESENVOLVIMENTO DE PRODUT0, 2., 2000, São Carlos. Anais... São Carlos: 2000.

DOOLEY, K.; JOHNSON, D. Changing the new product development process: reengineering or continuous quality improvement? Measuring Business Excellence, v. 5-4, p. 32-38, 2001.

EISENHARDT, K. M. Building Theories from Case Study Research. Academy of Management Review, v. 14, n. 4, p. 535-550, 1989 .

ESTORILIO, C. C. A. O trabalho dos engenheiros em situações de projeto de produto: Uma análise de processo baseada na ergonomia. 2003. 317 f. Tese (Doutorado em Engenharia)Universidade de São Paulo, São Paulo, 2003.

FLEURY, A. Planejamento do projeto de pesquisa e definição do modelo teórico. In: CAUCHICK MIGUEL, P. A. (Org.). Metodologia de pesquisa em engenharia de produção e gestão de operações. Rio de Janeiro: Elsevier, 2010. p. 3344.

FREDERICKS, E. Cross-functional involvement in new product development. Qualitative Market Research: An International Journal, v. 8, n. 3, p. 327-341, 2005. http:// dx.doi.org/10.1108/13522750510603370

FREITAS, C. Uma proposta de avaliação da reestruturação do processo de desenvolvimento de produtos baseada em métricas. 2004. 124 f. Dissertação (Mestrado Profissionalizante)-Universidade Federal do Rio Grande do Sul, Porto Alegre, 2004.

GODOY, A. S. Introdução à Pesquisa Qualitativa e suas Possibilidades. Revista de Administração de Empresas, v. 35, n. 2, p. 57-63, 1995.

GRIFFIN, A. The effect of project and process characteristics on product development cycle time. Journal of Marketing Research, v. 34, n. 1, p. 24-35, 1997. http://dx.doi. org/ $10.2307 / 3152062$
HAQUE, B.; PAWAR, K. S.; BARSON, R. J. The application of business process modelling to organisational analysis of concurrent engineering environments. Technovation, v. 23, p. 147-162, 2003. http://dx.doi.org/10.1016/ S0166-4972(01)00103-1

HART, S. et al. Industrial company's evaluation criteria in new product development gates. Journal of Product Innovation Management, v. 20, p. 22-36, 2003. http:// dx.doi.org/10.1111/1540-5885.201003

HOLMES, M. F.; CAMPBELL, R. B. Improving product development processes along three key vectors leads to greatly improved business performance. MIT Center for Innovation in Product Development Conference, p. 1-17, 2002.

HUANG, X. Managing new product development in the Chinese steel industry: an empirical investigation. International Journal Technology Management, v. 24, n. 5-6, p. 557-568, 2002. http://dx.doi.org/10.1504/ 1JTM.2002.003070

KENNY, J. Effective project management for strategic innovation and change in an organizational context. Project Management Journal, v. 34, n. 1, p. 43-53, 2003.

KIM, J.; WILEMON, D. Sources and assessment of complexity in NPD projects. $R \& D$ Management, v. 33, n. 1, p. 15-30, 2003. http://dx.doi.org/10.1111/14679310.00278

KRISHNAN, V.; ULRICH, K. T. Product Development Decisions: A review of the Literature. Management Science, v. 47, n. 1, p. 1-21, 2001. http://dx.doi.org/10.1287/ mnsc.47.1.1.10668

KRISHNAN, V.; LOCH, C. H. A retrospective look at production and operations management articles on new product development. Production and Operations Management, v. 14, n. 4, p. 433-441, 2005. http://dx.doi. $\operatorname{org} / 10.1111 / \mathrm{j} .1937-5956.2005 . t b 00231 . x$

LAGER, T. A structural analysis of process development in process industry. R\&D Management, v. 32, n. 1, p. 87-95, 2002. http://dx.doi.org/10.1111/1467-9310.00241

LARSEN, M.; KIM, J. Integrating statistics into product development. Quality Congress, p. 549-560, 2001.

LESTER, D. H. Critical success factors for new product development. Research Technology Management, v. 41, n. 1, p. 36-43, 1998.

LINT, 0.; PENNINGS, E. The Option Approach to the New Product Development Process. Netherlands: Erasmus University Rotterdam, Eindhoven University of Technology, and Catholic University of Leuven, 1999. 38 p.

CAUCHICK MIGUEL, P. A. Estudo de caso na engenharia de produção: estruturação e recomendações para sua condução. Produção, v. 17, n. 1, p. 216-229, 2007. http:// dx.doi.org/10.1590/S0103-65132007000100015

MUNDIM, A. P. F. et al. Aplicando o cenário de desenvolvimento de produtos em um caso prático de capacitação profissional. Gestão \& Produção, v. 9, n. 1, p. 1-16, 2002.

NAMBISAN, S. Information systems as a reference discipline for new product development. MIS Quarterly, v. 27, n. 1, p. 1-18, 2003.

NILSSON-WITELL, L.; ANTONI, M.; DAHLGAARD, J. J. Continuous improvement in product development: Improvement programs and quality principles. The International Journal of Quality \& Reliability Management, v. 22, n. 8, p. 753-768, 2005. http://dx.doi. org/10.1108/02656710510617210 
NOBELIUS, D. Linking product development to applied research: transfer experiences from an automotive company. Technovation, v. 24, p. 321-334, 2004. http:// dx.doi.org/10.1016/S0166-4972(02)00073-1

O'CONNOR, P. Implementing a stage-gate process: a multicompany perspective. Journal of Product Innovation Management, v. 11, n. 3, p. 183-200, 1994. http://dx.doi. org/10.1016/0737-6782(94)90002-7

OZER, M. New product development in Asia: An introduction to the special issue. Industrial Marketing Management, v. 35, p. 252-261, 2006. http://dx.doi.org/10.1016/j. indmarman.2005.12.005

PAULA, G. M. Estudo da competitividade de cadeias integradas no Brasil: impacto das zonas de livre comércio. Campinas: UNICAMP, Instituto de Economia, 2002. 226 p.

PRASAD, B. Concurrent engineering fundamentals: integrated product and process organization. New Jersey: Prentice Hall International Series, 1997.

PUGH, S. Creating innovative products using total design: the living legacy of Stuart Pugh. Massachusetts: AddisonWesley, 1996.

ROZENFELD, H. Para integrar a manufatura é importante o domínio dos business process. Máquinas e Metais, p. 32-47, 1996.

ROZENFELD, H. et al. Gestão de Desenvolvimento de Produtos: uma referência para a melhoria do processo. São Paulo: Saraiva, 2006.

SHANE, S. A.; ULRICH, K. T. Technological Innovation, Product Development, and Entrepreneurship in Management Science. Management Science, v. 50, n. 2, p. 133-144, 2004. http://dx.doi.org/10.1287/mnsc. 1040.0204

SILVA, S. L. Proposição de um modelo para caracterização das conversões do conhecimento no processo de desenvolvimento de produtos. 2002. $245 \mathrm{f}$. Tese (Doutorado em Engenharia Mecânica)-Universidade de São Paulo, São Carlos, 2002.

SONG, M.; NOH, J. Best new product development and management practices in the Korean high-tech industry. Industrial Marketing Management, v. 35, p. 262-278, 2006. http://dx.doi.org/10.1016/j.indmarman.2005.04.007
SYAMIL, A.; DOL, W. F.; APIGIAN, C. H. Process performance in product development: measures and impacts. European Journal of Innovation Management, v. 7, n. 3, p. 205-217, 2004. http://dx.doi. org/10.1108/14601060410549892

THIA, C. W. et al. An exploratory study of the use of quality tools and techniques in product development. The TQM Magazine, v. 17, n. 5, p. 406-424, 2005. http://dx.doi. org/10.1108/09544780510615924

THIEME, R. J.; SONG, X. M.; SHIN, G. Project management characteristics and new product survival. The Journal of Product Innovation Management, v. 20, p. 104-119, 2003. http://dx.doi.org/10.1111/1540-5885.2002004

TON1OL1, J. N. A integração entre o processo de desenvolvimento de produto e o gerenciamento da cadeia de suprimentos e sua relação com o papel desempenhado pelo engenheiro de produto. 2003. 156f. Dissertação (Mestrado)-Universidade de São Paulo, São Paulo, 2003.

VALERI, S. G. Estudo do processo de revisão de fases no processo de desenvolvimento de produtos em uma indústria automotiva. 2000. 109 f. Dissertação (Mestrado) -Universidade de São Paulo, São Carlos, 2000.

VAN OORSCHOT, K. E.; BERTRAND, J. W. M.; RUTTE, C. G. Field studies into the dynamics of product development tasks. International Journal of Operations \& Production Management, v. 25, n. 8, p. 720-739, 2005. http://dx.doi. org/10.1108/01443570510608574

VOSS, C.; TSIKRIKTSIS, N.; FROHLICH, M. Case Research in Operations Management. International Journal of Operations and Production Management, v. 22, n. 2, p. 195-219, 2002. http://dx.doi. org/10.1108/01443570210414329

ZANCUL, E. S.; MARX, R.; METZKER, A. Organização do trabalho no processo de desenvolvimento de produtos: a aplicação da engenharia simultânea em duas montadoras de veículos. Gestão \& Produção, v. 13, n. 1, p. 15-29, 2006.

YIN, R. G. Case study research - design and methods. London: Stage, 2001.

\title{
Production preparation process analysis in new products development - a case study in the steel industry
}

\begin{abstract}
The demand for new products has increased in some companies from the steel industry, indicating a growing concern with the performance of products development process (PDP), which depends on several important conceptual elements found in the literature. The production process project is a relevant factor in a steel company, because it is a continuous manufacturing process and it generally involves significant investments in the production preparation phase. In this context, the present paper analyzes this stage of the process in a steel producer. The research aims to identify, through a case study methodological approach, the company's organizational practices with focus on the operational aspects and their interfaces involving the functional areas of marketing, product engineering and manufacturing. The study also analyzes the integration of multidisciplinary teams, the decision-making and the criteria forthe PDP results evaluation. It was concluded that the analyzed company makes use of practices that structure the production preparation and that the inter-functional integration of the areas is the main factor of the DPD success.
\end{abstract}

\section{Keywords}

Product development process (PDP). Process Project. Steel industry. 